\title{
He-Cooled Divertor for Demo: Technological Study on Joining Tungsten Components with Titanium Interlayer
}

\author{
Prachai Norajitra, Widodo Widjaja Basuki, Luigi Spatafora, Ulrike Stegmaier
}

\section{- Introduction}

- The He-cooled divertor concept HEMJ for DEMO (Fig. 1) has been investigated at KIT with aim to reach $10 \mathrm{MW} / \mathrm{m}^{2}$. - HEMJ design uses: impinging He jets @ $10 \mathrm{MPa}, 600^{\circ} \mathrm{C}$, - hexa. W tile (SW 18) brazed to WL10 thimble ( $\varnothing 15 \times 1 \mathrm{~mm})$, - modular system: 1-finger, 9-finger modules, div. cassette, - ODS Eurofer structure (connection via transition pieces).

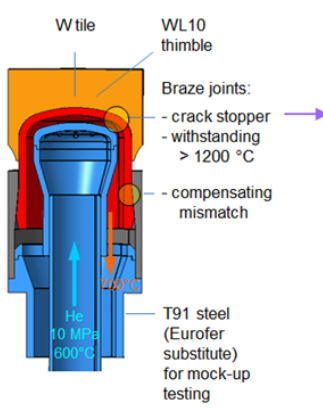

1-finger module

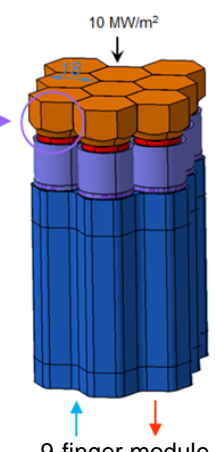

9-finger module

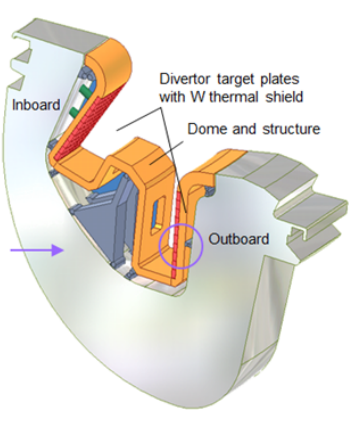

divertor cassette
Fig. 1: He-cooled modular divertor with jet cooling (HEMJ).

\section{- Requirements for the $\mathbf{W}-\mathbf{W}$ joint:}

- Crack stopper function (sufficient toughness of interlayer)

a Resisting high operating joint temperature $>1200^{\circ} \mathrm{C}$

- Using low-activation interlayer material, having:

- high melting point, high thermal conductivity, high toughness,

a and good bonding capability with W (no intermetalic phase)

$\rightarrow$ This leads to the use of Titanium $\left(\mathrm{Tm}=1668^{\circ} \mathrm{C}\right)$ as interlayer.

- Method A): W-W brazing with Ti interlayer (Fig. 2)

- Using induction furnace,

- a stack of samples: W cylinder ( $(12 \times 12)$, Ti sheet

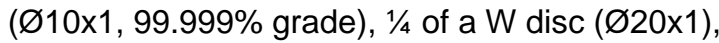

- aceton sample cleaning,

- pyrometer $\mathrm{T}$ measurement (range $500-2000^{\circ} \mathrm{C}$, accy $\pm 50^{\circ} \mathrm{C}$ ).

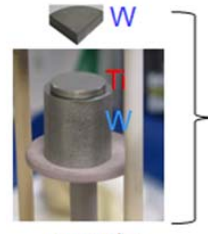

sample arrangement

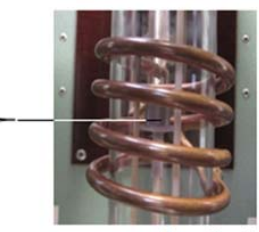

vacuum glas flask with inductor coil

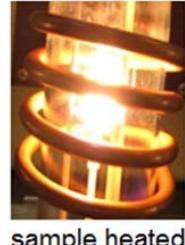

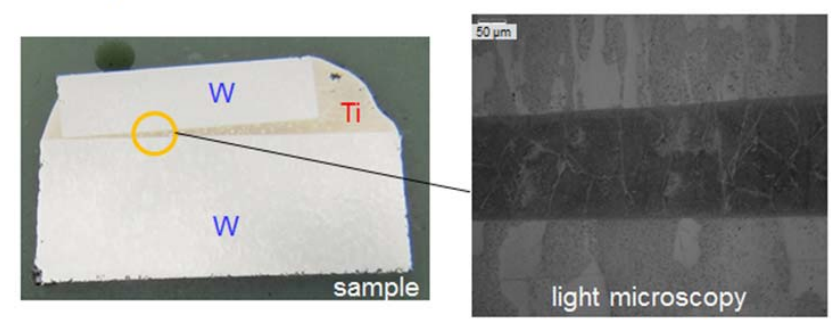

Fig. 2: W-W brazing test w. Ti interlayer in induction furnace.
- W-W brazing procedure:

- sample glass flask flushed with argon and evacuated @ 1 mbar, a brazing temp. $\sim 1820^{\circ} \mathrm{C} @ \mathrm{~W}$ surface (heating rate $\sim 2 \mathrm{~K} / \mathrm{s}$ ), - hold time $\sim 2.5 \mathrm{~min}$ (total $12 \mathrm{~min}$ ).

- Results: no cracks and delamination of flat W-Ti interfaces, but - undesired W grain growth and W diffusion phase in Ti observed.

- Method B): W-W diffusion bonding with Ti interlayer (Fig. 3) - Using vacuum furnace (a) with unaxial pressing device,

- WL10 thimble and tile-like W cyl. sample (99.97 wt\% purity) with true to original interface geometry (b),

- Ti sheet (Ø10x1, 99.999\% grade, 3 pieces) (b),

aceton sample cleaning.

- Diffusion bonding (DB) procedure:

a bonding temp. $\sim 900{ }^{\circ} \mathrm{C}$,

- constant displacement rate of $1 \mu \mathrm{m} / \mathrm{s}$,

- max. surface pressure $2150 \mathrm{MPa}$,

- hold time $\sim 1 \mathrm{~h}$,

- vacuum $\sim 5 \cdot 10^{-5}$ mbar.

- Results: perfect bonding of W-Ti at interfaces (c) (d),

- no $\mathrm{W}$ grain growth and negligibly small $\mathrm{W}$ inter-diffusion layer in $\mathrm{Ti}$ observed (d) (e),

- no excessive hardness along the joint interfaces (f).

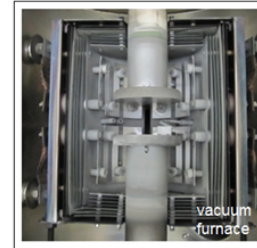

(a) vacuum furnace

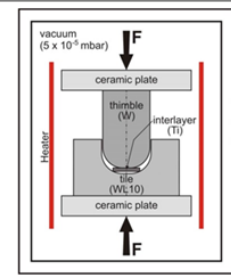

(b) exp. setup
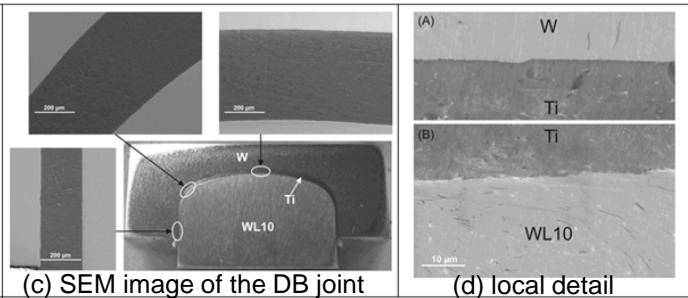

(d) local detail

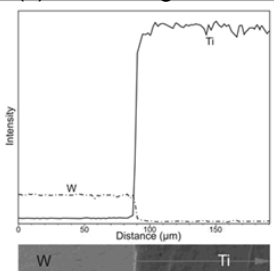

EDX (e) and nano inden
Fig. 3: Diffusion bonding of W-W connection with Ti interlayer.

\section{- Conclusion and outlook}

- Both investigated brazing and diffusion bonding methods for joining tungsten parts with $\mathrm{Ti}$ interlayer have shown error-free and satisfactory results.

- Nevertheless, the latter proofs to be the better method because of the non-occurence of grain coarsening and the occurrence of negligibly small inter-diffusion layer.

- Future R\&D needs: Characterization of the joint and investigation of its behavior under neutron irradiation. 